\title{
Thermal Limits of Men in Moderate to Heavy Work in Tropical Farming
}

\author{
Pranab Kumar NAG*, Anjali NAG and Shirish Pratap ASHTEKAR \\ National Institute of Occupational Health, Indian Council of Medical Research, Ahmedabad 380 016, India \\ Received February 24, 2006 and accepted September 29, 2006
}

\begin{abstract}
The farmers in tropical climate are exposed to high heat during the summer months. The study examined the physiological strains of farmers $(\mathrm{N}=26)$ to six combined exposures of work and high heat, with moderate and heavy work $\left(26\right.$ to $50 \%$, and 51 to $\left.75 \% \mathrm{VO}_{2 \max }\right)$ and three ambient conditions, i.e., 34.4 to $42.2^{\circ} \mathrm{C}$ WBGT (inside) in an environmental chamber. While the cardiorespiratory responses and $T_{\text {cr }}$ were predominantly influenced by the work severity $(p<0.001)$, the environmental warmth greatly influenced the sweating response $(p<0.001)$. The importance was placed on the segmental $T_{\text {sk }}$ as the first rank indicator of the bodily heat strain. Both the environmental warmth and work severity had independent discernable effects on the dynamic equilibrium of the central and peripheral mechanism to regulate the body temperature. The segmental and compartmental (core, muscle, fat and skin) heat balance analysis indicated the span of convergence of the segmental core and muscle temperatures to the divergence of skin and fat temperatures (CORE$S H E L L)$ as a quantitative estimate of the segmental gradient for heat transfer. The summation of heat exchange across the compartments and segments yielded the transient change in $T_{\text {cr }}(0.06$ to $0.12^{\circ} \mathrm{C} / \mathrm{min}$ ), with significant difference between the moderate and heavy work. The $T_{\mathrm{cr}}$ of $39^{\circ} \mathrm{C}$ was taken as the limit of tolerance for the farmers, and by defining the criteria limit of $T_{\text {cr }}$ of $\sim 2.5^{\circ} \mathrm{C}$ gradient from the basal $T_{\mathrm{cr}}$ and the rate of change in $T_{\mathrm{cr}}$, the tolerance times were estimated. Corollary to the development of ISO 7933 standard (PHS index), the predictions of tolerance times from the transient change in $T_{\text {cr }}$ or the exponential relationship with the WBGT (tolerance time, $\min =1,841$ $e^{-0.103 \text { WBGT }}$ ) were useful to suggest the protective limit for men at work in extremely hot environment. The simplicity of prediction lies in using WBGT as a criterion. The exponential equation estimated the tolerance time of $55 \mathrm{~min}$ at $34^{\circ} \mathrm{C}$ WBGT, and up to $38^{\circ} \mathrm{C}$ WBGT, the decrease in tolerance time was 4 to 5 min per degree increase in environmental warmth. Beyond $38^{\circ} \mathrm{C} \mathrm{WBGT}$, the estimated tolerance time decreased by 2 to 3 min per degree increase in WBGT. Further optimization and validation of the knowledge for men and women farmers in different age groups will have application in managing heat illnesses and disorders in tropical farming.
\end{abstract}

Key words: Tropical climate, Heat stress, WBGT, Physiological responser, Compartmental heat exchange, Tolerance limit

\section{Introduction}

Developing guidelines for safe human exposure to tropical hot environments is imperative. The international agencies ${ }^{1-6)}$ have developed guidelines and criteria documents in reducing risks of heat induced illnesses and optimizing limit of

*To whom correspondence should be addressed. exposures in hot environment. Apart from the differences in physiological criteria in arriving at allowable exposure or danger limit of imminent heat collapse ${ }^{7,8)}$, inherent difficulties exist that the reference environmental and population characteristics covered in the guidelines do not generally reflect the extreme climates of the tropics ${ }^{9}$. The effective heat load on human beings has both facets of 
external or environmental, and internal or metabolic conditions; however, the information on the effects of heat on health, performance and safety for the workers engaged in tropical farming is scarce ${ }^{10)}$. The tobacco harvesters and tea pluckers in rural India ${ }^{11,12)}$ have, for example, high prevalence of malaria, iron deficiency and anemia, with endemic consequences on their working capacities and heat disorders. Knowledge of the factors such as the environmental severity, physical work performed, euhydration, gender, individual susceptibility and acclimatization $^{13,14)}$ that modify the physiological strains ${ }^{15-17)}$ might improve exposure guidelines for the population concerned. With reference to conditions that prevail in outdoor tropical farming during the summer months, this contribution describes a direct longitudinal study that elucidates the magnitude of physiological strains of farm workers in simulated exposures to hot-dry and hot-humid environments, and examines the interactive effects of work severity and environmental warmth on the thermoregulatory functions. The study explores the mechanistic heat exchange across the body segments to estimate the transient body temperature build-up, and predict the limit of tolerance to work in hot environments.

\section{Materials and Methods}

The study was undertaken in the city of Ahmedabad (western part of India), and this region is extremely hot during the summer months. A group of twenty six young, male farmers from the nearby villages (age $-26 \pm 3 \mathrm{yr}$; stature$163.6 \pm 6.5 \mathrm{~cm}$; body weight $-49.6 \pm 6.7 \mathrm{~kg}$; body surface area $-1.50 \pm 0.15 \mathrm{sqm} ; \mathrm{VO}_{2 \max }-2.04 \pm 0.22 \mathrm{l} / \mathrm{min}$ ) volunteered to undergo exposures in a walk-in environmental chamber (Hotpack International, USA). On indoctrination about the experimental procedure, the volunteers gave their informed consent to participate, as per the ethical guidelines ${ }^{18}$. Selection of farmers was based upon evidence of their good health and absence of complicating factors such as cardiovascular and pre-existing pulmonary problems.

Corresponding to the tropical conditions to which the farmers are habitually exposed in the summer months, the experimental protocol included six combined exposures of work and heat-moderately heavy and heavy physical work, and three ambient conditions of the wet bulb-globe temperature, WBGT (inside) (weighted over time) ranged between 34.4 and $42.2^{\circ} \mathrm{C}$. The braking loads for ergometric work were equivalent to 26 to $50 \%$, and 51 to $75 \%$ of one's aerobic capacity $\left(\mathrm{VO}_{2 \max }\right)$. The air speed $(\mathrm{v})$ in the chamber varied within 0.4 to $0.6 \mathrm{~m} / \mathrm{sec}$. The ambient conditions of the experiment, including dry-bulb $\left(\mathrm{t}_{\mathrm{a}}\right)$, wet-bulb $\left(\mathrm{t}_{\mathrm{wb}}\right)$ and globe $\left(\mathrm{t}_{\mathrm{g}}\right)$ temperatures are presented in Table 1.

All volunteers were exposed to six conditions in different days during the first half of the day. The study was undertaken with randomized intermittent days of exposure (two to three days interval). Each volunteer attended the laboratory for six to seven days over a period of $3 \mathrm{wk}$. The physiological responses-body core $\left(\mathrm{T}_{\mathrm{cr}}\right)$ and segmental skin $\left(\mathrm{T}_{\mathrm{sk}}\right)$ temperatures, metabolic rate, heart rates and sweating responses were monitored. The $\mathrm{T}_{\text {cr }}$ was monitored, using a deep body thermometer (Deep Body Thermometer Ltd, UK), designed on the principle of creating a zone of zero heat flow across the body shell ${ }^{19}$. Once the initial stabilization of the thermometer was achieved, the recording of the gradual changes in the $\mathrm{T}_{\text {cr }}$ was satisfactory ${ }^{20)}$. The $\mathrm{T}_{\text {sk }}$ of six locations (forehead, trunk, upper arm, hand, thigh, and feet) was monitored using a multi-channel telethermometer (Aplab, India). The oxygen uptake was determined from the pulmonary ventilation and concentration of oxygen in the expired air, using a paramagnetic oxygen analyzer (SyvronTaylor, U.K.). The sweat rate was measured as the net change in body weight after each exposure. The physiological responses of the volunteers were monitored for a maximum of $90 \mathrm{~min}$; however, the durations of exposure were primarily limited by the combined intensity of work and heat. The ambient conditions were grouped, therefore, to compare the interactive effects relative to physical work and heat stress. At higher severity of exposures, the criteria taken for discontinuing the exposure was the level of tolerance, i.e., incipient collapse, the $\mathrm{T}_{\text {cr }}$ limit of 39 to $39.5^{\circ} \mathrm{C}^{17)}$, or the gradual narrowing of gradient between the $\mathrm{T}_{\mathrm{cr}}$ and $\mathrm{T}_{\mathrm{sk}}{ }^{20)}$.

Conventionally, the thermal indices are utilized to integrate the climatic, physical and personal factors, and physiological responses to ascertain the environmental warmth ${ }^{21,22)}$. The ISO 7933 standard $^{3,4)}$, published first time in 1989, and revised in 2004 (evolved from a concerted research of eight European laboratories), uses a rational analysis of the heat balance equation between the human body and the environment. It has been adopted as a part of a series of standards concerning assessment of thermal environments. The earlier version of the ISO model ${ }^{3)}$ estimates the sweat rate that would be required to achieve thermal equilibrium, and predicts warning and danger allowable exposure limits corresponding to increases in $\mathrm{T}_{\text {cr }}$ of 0.8 and $1.0^{\circ} \mathrm{C}$ respectively. The model $^{3)}$ has been evaluated in industrial and experimental settings and limitations documented of poor predictions ${ }^{7,8,23,24)}$. The revised standard ${ }^{4}$ includes amendments in the algorithms (renamed as predicted heat strain, PHS index) to predict the transience of sweat rate and internal core temperature 
Table 1. Severity of work and ambient conditions of the experimental exposures in the environmental chamber

\begin{tabular}{|c|c|c|c|c|c|c|}
\hline \multirow{2}{*}{$\begin{array}{l}\text { Severity of } \\
\text { work }\end{array}$} & \multirow{2}{*}{$\begin{array}{l}\text { Examples of farm activities categorized as } \\
\text { moderate and heavy work }{ }^{29)}\end{array}$} & \multicolumn{5}{|c|}{ Experimental conditions } \\
\hline & & $\begin{array}{l}\text { Ambient } \\
\text { condition }\end{array}$ & $\begin{array}{c}\text { Dry bulb } \\
\text { temperature, } \\
\mathrm{t}_{\mathrm{a}}\left({ }^{\circ} \mathrm{C}\right)\end{array}$ & $\begin{array}{c}\text { Globe } \\
\text { temperature, } \\
\mathrm{t}_{\mathrm{g}}\left({ }^{\circ} \mathrm{C}\right)\end{array}$ & $\begin{array}{c}\text { Wet bulb } \\
\text { temperature, } \\
\mathrm{t}_{\mathrm{wb}}\left({ }^{\circ} \mathrm{C}\right)\end{array}$ & $\begin{array}{l}\text { WBGT } \\
\text { (inside) } \\
\left({ }^{\circ} \mathrm{C}\right)\end{array}$ \\
\hline \multirow[t]{3}{*}{$\begin{array}{l}\text { Moderately } \\
\text { heavy }\end{array}$} & $\begin{array}{l}\text { Sowing, uprooting and transplanting seedling (by } \\
\text { hand), fertilizer/pesticide broadcasting, knapsack }\end{array}$ & 1 & $42.0 \pm 3.5$ & $44.0 \pm 2.8$ & $30.2 \pm 2.5$ & $34.4 \pm 1.5$ \\
\hline & $\begin{array}{l}\text { spraying of pesticides, harvesting paddy using } \\
\text { sickle, cutting sugarcane, winnowing, water }\end{array}$ & 2 & $43.9 \pm 3.5$ & $45.5 \pm 2.8$ & $33.8 \pm 1.0$ & $37.3 \pm 0.7$ \\
\hline & $\begin{array}{l}\text { channeling work, tractor disc ploughing, power } \\
\text { tiller rotapuddling and rotatilling. }\end{array}$ & 3 & $47.5 \pm 2.5$ & $48.5 \pm 2.0$ & $39.5 \pm 2.1$ & $42.2 \pm 1.5$ \\
\hline \multirow[t]{3}{*}{ Heavy work } & $\begin{array}{l}\text { Ploughing (country and mould board plough), } \\
\text { bund trimming, hoeing, germinating manual }\end{array}$ & 4 & $42.3 \pm 3.0$ & $44.2 \pm 2.4$ & $30.8 \pm 1.2$ & $34.9 \pm 0.9$ \\
\hline & $\begin{array}{l}\text { seeders, paddy transplanter (powered), weeding } \\
\text { (weeders/hand tool), self-propelled paddy }\end{array}$ & 5 & $42.4 \pm 4.1$ & $44.3 \pm 3.3$ & $34.1 \pm 1.8$ & $37.1 \pm 0.8$ \\
\hline & $\begin{array}{l}\text { harvester, load carrying on head and yoke } \\
\text { ( } 40 \text { to } 80 \mathrm{~kg} \text { ),threshing paddy by manual } \\
\text { beating/pedal thresher, water lifting using } \\
\text { swing basket, pounding grain. }\end{array}$ & 6 & $45.8 \pm 2.4$ & $47.1 \pm 2.0$ & $38.9 \pm 1.7$ & $41.4 \pm 1.5$ \\
\hline
\end{tabular}

Values are means \pm standard deviations

responses, and the maximum allowable exposure durations.

Considering the application of extremely hot outdoor farming environment, and the objective to explore the mechanistic heat exchange across the body compartments, the current analysis adopted a biophysical approach ${ }^{25,26)}$. This examined the heat exchanges through different avenues across the segments (i.e., head, trunk, arm, hand, leg and feet) and body layers-blood, core (viscera plus skeleton), muscle, fat and skin (i.e., 6 segments $\times 5$ layers $=30$ compartments). The estimated fractions of the body segments and compartments in terms of the whole body weight are shown in Fig. 1. The heat exchange within the body segments takes place by conduction along the adjacent compartments and reaches to the outer skin, which is primarily responsible for heat exchanges with the environment through convection, radiation and evaporation. Accordingly, the general thermodynamic equation of heat balance of each segment (when storage $\delta \mathrm{H}=0$ ) was expressed as follows:

$$
\begin{aligned}
& \mathrm{Y} \Delta \mathrm{T} / \Delta \mathrm{t}= \\
& (\mathrm{V} \rho \times \mathrm{S})_{\text {Blood }} \times\left(\mathrm{T}_{\text {Blood }}\right)+\Delta \mathrm{M}-\left[\left\{\mathrm{K}_{\text {Blood-Core }}\left(\mathrm{T}_{\text {Blood }}-\mathrm{T}_{\text {Core }}\right)+\right.\right. \\
& \mathrm{K}_{\text {Core-Muscle }}\left(\mathrm{T}_{\text {Core }}-\mathrm{T}_{\text {Muscle }}\right)+\mathrm{K}_{\text {Muscle-Fat }}\left(\mathrm{T}_{\text {Muscle }}-\mathrm{T}_{\text {Fat }}\right)+\mathrm{K}_{\text {Fat-Skin }} \\
& \left.\left(\mathrm{T}_{\text {Fat }}-\mathrm{T}_{\text {Skin }}\right)+\mathrm{H}(\mathrm{i})\left(\mathrm{T}_{\text {Skin }}-\mathrm{T}_{\text {Environment }}\right)\right\} \times \mathrm{SA}+\left(\mathrm{C}_{\text {Res }}+\mathrm{E}_{\text {Res }}+\right.
\end{aligned}
$$

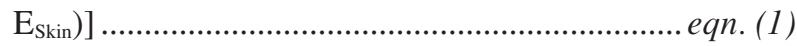

where $\mathrm{Y}$, product of compartmental mass and specific heat,
$\Delta \mathrm{T} / \Delta \mathrm{t}$, change in temperature with time, $\mathrm{V}$, volume (liter), $\rho$, density $(\mathrm{kg} / \mathrm{L}), \mathrm{S}$, specific heat of blood (W.h $\left./ \mathrm{kg} .{ }^{\circ} \mathrm{C}\right), \Delta$ M, (total-basal metabolic energy, W.h), K, conductance of body compartments $\left(\mathrm{W} / \mathrm{m}^{2} .{ }^{\circ} \mathrm{C}\right)$, $\mathrm{T}$, resultant body temperature $\left({ }^{\circ} \mathrm{C}\right), \mathrm{H}(\mathrm{i})$, combined heat transfer coefficients of segments $\left(\mathrm{W} / \mathrm{m}^{2} .{ }^{\circ} \mathrm{C}\right)^{27)}, \mathrm{SA}$, surface area $\left(\mathrm{m}^{2}\right), \mathrm{C}_{\mathrm{Res}}$ and $\mathrm{E}_{\mathrm{Res}}$, respiratory heat loss through convection and evaporation (W.h), $\mathrm{E}_{\text {Skin }}$, evaporative heat loss from skin (W.h) ${ }^{28}$. The computation of the components in the equation yielded the rate of change in segmental and compartmental temperatures, and the overall build-up of the internal core temperature.

Data analysis was performed using the statistical package for the social sciences (SPSS 6.1.5). The descriptive statistics ascertained the relative magnitude of the physiological strains of the farmers, and the repeated measure analysis of variance (ANOVA) was undertaken to find out the interactive effects of work severity and heat stress on the thermoregulatory parameters. In view of the multiple comparison of the variance between the work severity, heat stress and test measures, the sum of squares of variance (SS) was expressed as percentage of the total SS. Tukey's HSD (honestly significant difference) test was applied to produce the post hoc multiple comparisons of the experimental conditions and test measures. The regression analysis was carried out to determine the interrelationships between the heat exchange and the physiological parameters. 


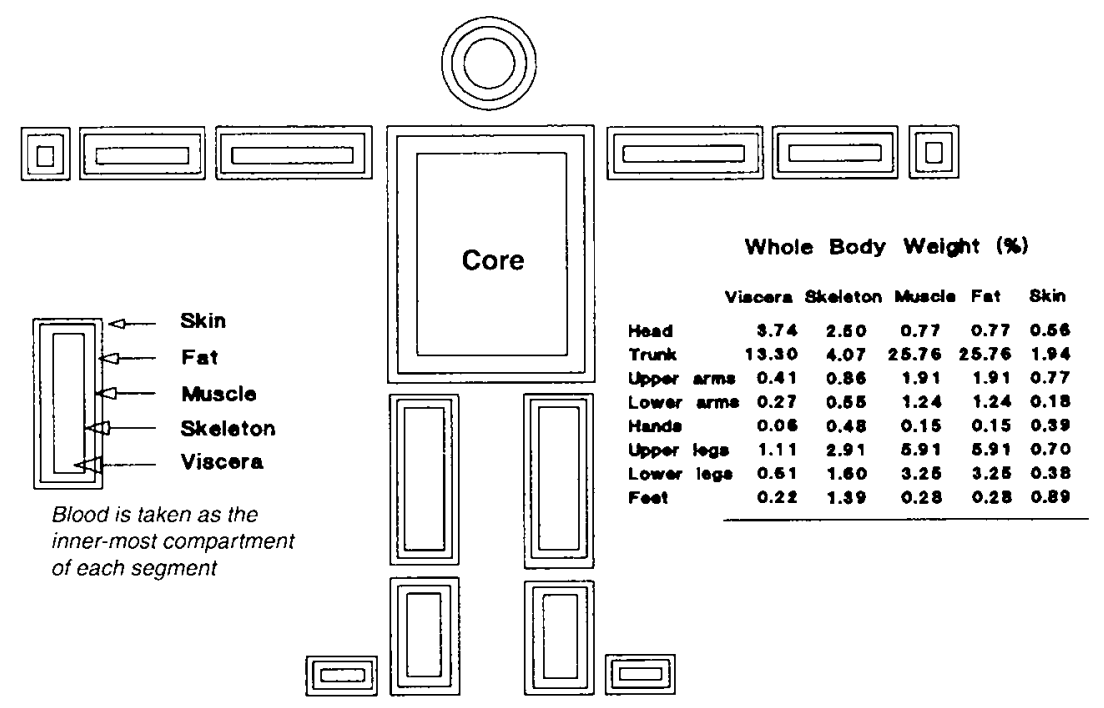

Fig. 1. Body segments and compartments in biophysical analysis of heat exchange characteristics in men.

\section{Results}

\section{Range of exposures}

The experimental exposures outlined in Table 1 essentially covered the very hot climatic conditions, with $\mathrm{t}_{\mathrm{a}}$ ranged between 38 to $50^{\circ} \mathrm{C}, \mathrm{t}_{\mathrm{wb}}-27$ to $42^{\circ} \mathrm{C}$ and $\mathrm{t}_{\mathrm{g}}-41$ to $51^{\circ} \mathrm{C}$ respectively. The metabolic rates ranged between 275 and 600 W.h. During the exposures in the environmental chamber, the volunteers wore shorts, with approximate clothing insulation of 0.3 clo. Generally, during farming work, the farmers might be wearing shorts or a lungi (a loose fabric wrapped around at the ankle length), and a half-sleeve banian or t-shirt with insulation level ranged within 0.4 to 0.6 clo.

\section{Magnitude of the thermoregulatory functions}

With reference to one's $\mathrm{VO}_{2 \max }$, the indicative moderate and heavy work, and three ranges of WBGT (Table 1) were grouped to analyze the heat exchange characteristics and effective load on the thermoregulatory functions. The combined stress imposed significant thermal load on the farmers, with potential health consequences. For the selected farmers, the oxygen demands in moderate and heavy work at different environmental warmth are shown in Fig. 2. The trend indicated that apart from a large difference in oxygen demands between the work severities, the environmental warmth had only a narrow influence on oxygen demands. On the other hand, the heart rates (Fig. 3) tended upward at a rate of 1 heart beat and 1.5 beats per degree rise in WBGT during the moderate and heavy work respectively. Similarly, the farmers had a linear rise in the rate of sweating with higher environmental warmths, as shown in Fig. 4. Since each litre of sweat evaporated from the skin surface represented a loss of nearly $675 \mathrm{~W}$ of heat, the extent of sweating was a large potential source of cooling, provided all the sweat was evaporated. The difference in the sweating response between moderate and heavy work became noticeable at the higher levels of environmental warmth (e.g., 41.4 and $42.2^{\circ} \mathrm{C} \mathrm{WBGT}$ ).

The heat gain outstripped heat loss, and as a result, a distinctive difference in $T_{\text {cr }}$ (Fig. 5) was noted in moderate and heavy workload with the increasing environmental stress. The gradual build up of the $\mathrm{T}_{\text {cr }}$ reached $39^{\circ} \mathrm{C}$ at $37.3^{\circ} \mathrm{C}$ WBGT during moderate work; whereas, in the case of heavy physical work the $\mathrm{T}_{\text {cr }}$ reached near to $39^{\circ} \mathrm{C}$ even at $34.9^{\circ} \mathrm{C}$ WBGT. The $\mathrm{T}_{\mathrm{cr}}$ was essentially in dynamic equilibrium supposedly maintained by the interaction of mechanism that allowed heat transfer to the periphery or shell and regulated the build up of body temperature. The profile of segmental $\mathrm{T}_{\mathrm{sk}}$ indicated the relative space for adjustment against the critically high levels of $\mathrm{T}_{\mathrm{cr}}$. The linear regression analysis (Table 2) indicated highly significant correlation $(p<0.001)$ between the WBGT index and the segmental $\mathrm{T}_{\mathrm{sk}}$. The slopes of the regression lines in moderately heavy work were relatively large, suggesting that the build up of the segmental $\mathrm{T}_{\text {sk }}$ with the increasing WBGT had greater space for thermoregulatory adjustment, compared to those in heavy work. The smaller slopes indicated slow build up of segmental $\mathrm{T}_{\text {sk }}$ in heavy work; however, the intercepts were larger due to higher levels of $\mathrm{T}_{\mathrm{sk}}$, compared to those in moderately heavy work. 


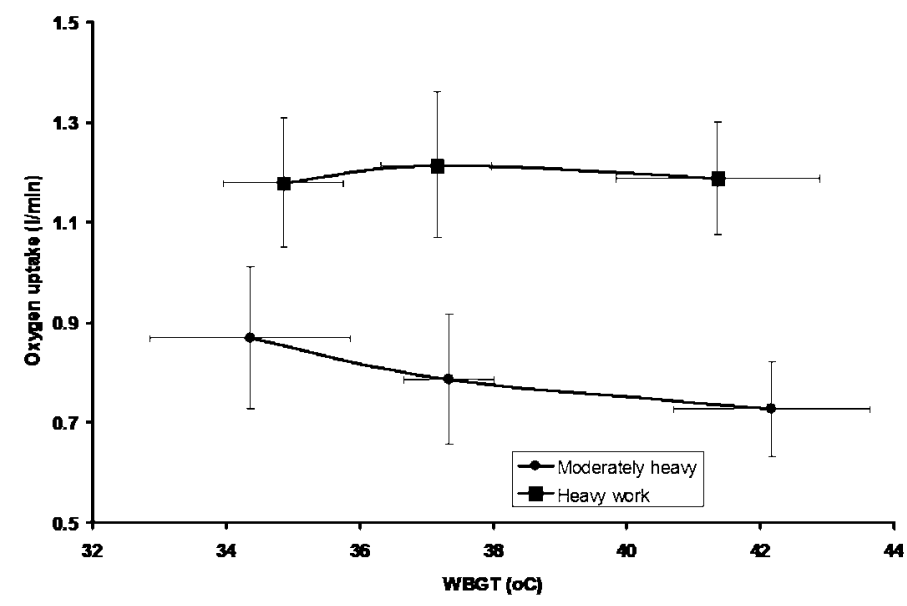

Fig. 2. Oxygen demands in moderate and heavy physical work at different environmental warmth.

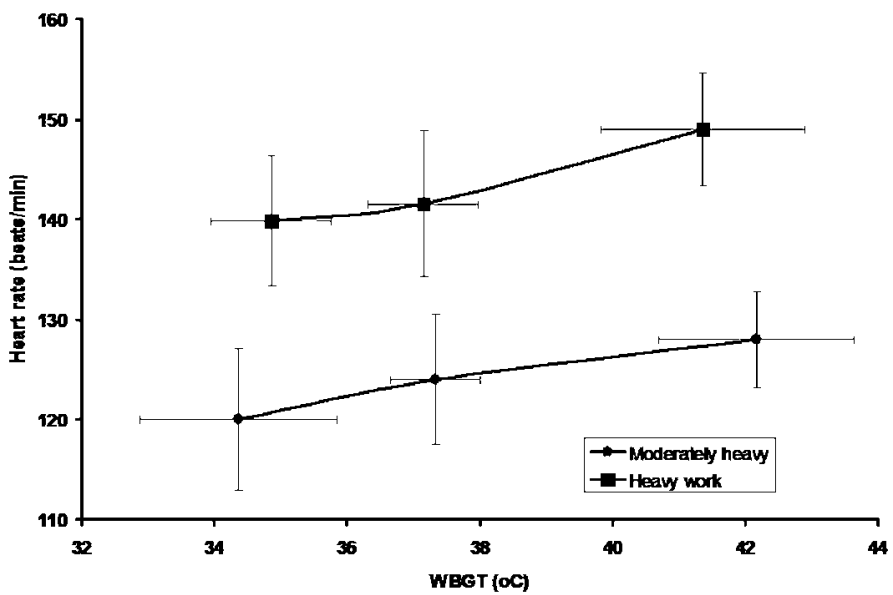

Fig. 3. Heart rate responses in moderate and heavy work at different environmental warmth.

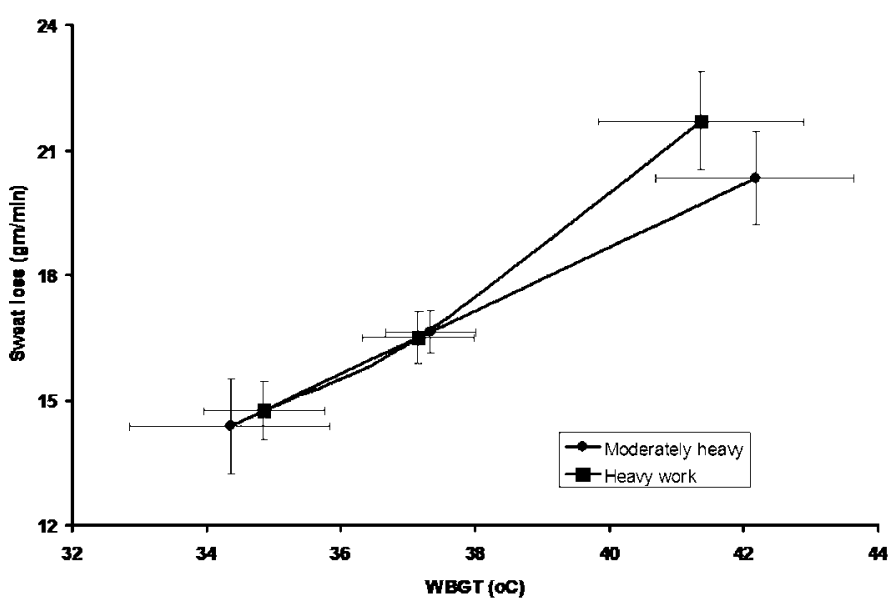

Fig. 4. Sweat loss in moderate and heavy work at different environmental warmth. 


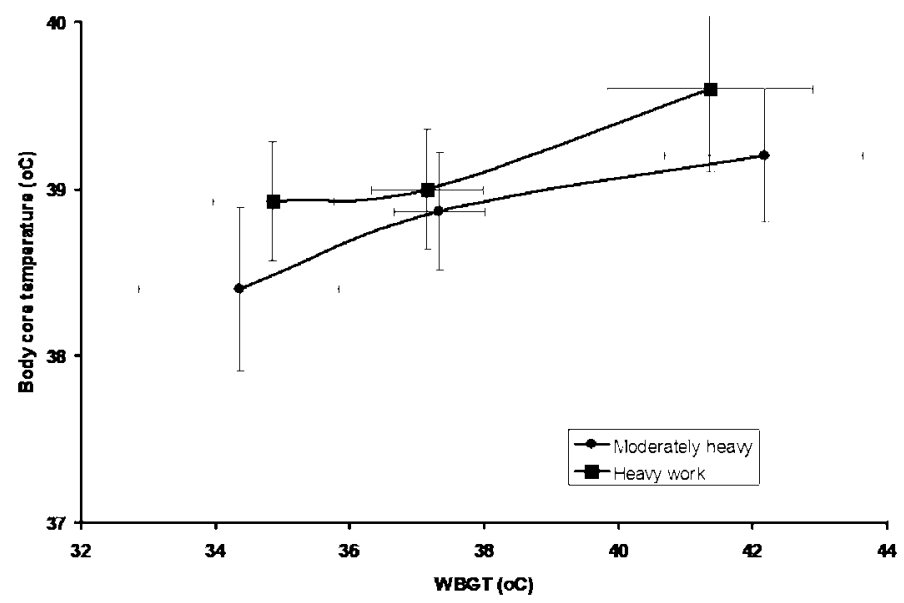

Fig. 5. Body core temperatures in moderate and heavy work at different environmental warmth.

Table 2. Regression equations and correlation coefficients between segmental skin temperatures and WBGT in moderate and heavy work

\begin{tabular}{llll}
\hline & Slope & Intercept & $\mathrm{R}^{*}$ \\
\hline Moderately heavy work & & & \\
$\mathrm{T}_{\text {sk }}$ (head) $=$ & 0.24 & 28.8 & 0.673 \\
$\mathrm{~T}_{\text {sk }}$ (trunk) $=$ & 0.23 & 28.6 & 0.716 \\
$\mathrm{~T}_{\text {sk }}$ (arm) $=$ & 0.28 & 26.9 & 0.583 \\
$\mathrm{~T}_{\text {sk }}$ (hand) $=$ & 0.28 & 27.0 & 0.727 \\
$\mathrm{~T}_{\text {sk }}$ (leg) $=$ & 0.28 & 27.0 & 0.727 \\
$\mathrm{~T}_{\text {sk }}$ (feet) $=$ & 0.26 & 27.5 & 0.686 \\
Heavy work & & & \\
$\mathrm{T}_{\text {sk }}$ (head) $=$ & 0.19 & 30.5 & 0.597 \\
$\mathrm{~T}_{\text {sk }}$ (trunk) $=$ & 0.20 & 29.8 & 0.585 \\
$\mathrm{~T}_{\text {sk }}$ (arm) $=$ & 0.22 & 29.0 & 0.615 \\
$\mathrm{~T}_{\text {sk }}$ (hand) $=$ & 0.22 & 29.3 & 0.615 \\
$\mathrm{~T}_{\text {sk }}$ (leg) $=$ & 0.22 & 29.1 & 0.605 \\
$\mathrm{~T}_{\text {sk }}$ (feet) $=$ & 0.18 & 30.3 & 0.545 \\
\hline
\end{tabular}

$* \mathrm{R}$ values are statistically highly significant $(p<0.001)$.

\section{Interactive effects of work and heat stress}

The interactive main effects of environmental warmth and physical work are documented in the results of the two-way ANOVA, given in Table 3. The oxygen demand and heart rates $(p<0.001)$, and the $\mathrm{T}_{\mathrm{cr}}$ responses $(p<0.05)$ were individually influenced by the work severity. The relative effects of work severity on the dimensions were much greater than would be expected by chance after allowing for the effects of environmental warmth. The sum of squares of the variance of oxygen demand, heart rates and $\mathrm{T}_{\text {cr }}$ responses due to the work severity explained $84.2,63.4$ and $6.3 \%$ of the total variance respectively. The interactions of work and heat stress on the cardio-respiratory responses were marginally significant $(p<0.05)$, explaining only $1.3 \%$ of the total variance. On the other hand, the rate of sweat loss was influenced by the environmental warmth $(p<0.001)$, with no significant interaction effect of work severity. Besides, both the environmental warmth $(p<0.001)$ and work severity $(p<0.001)$ had independent discernable effects on the segmental $\mathrm{T}_{\mathrm{sk}}$, together explaining about 39 to $48 \%$ of the total variance. The environmental effects on the segmental $\mathrm{T}_{\mathrm{sk}}$ appeared to be marginally greater than the effects of work severity; however, the interactive effects were not statistically significant. The results of the study are indicative that in high heat exposures exceeding $34^{\circ} \mathrm{C}$ WBGT, the body responded differently to the effects of work and heat stress, with the dominant effect reflected in the responses. The large deviations from the thermo-neutral reference provoked a distinctive nature of the peripheral response for feedback and regulation, and this was further substantiated in the compartmental heat exchange characteristics.

\section{Biophysical model of compartmental heat exchange}

The compartmental temperatures (core, muscle, fat and skin) were examined by a model application that included transient variation of the compartmental characteristics due to the change in the metabolic rate, resultant body temperature, and respiratory and evaporative heat loss from skin. The heat balance analysis of the compartments yielded the rate of change in $T_{\mathrm{cr}}$, which allowed estimating the tolerance time. The schematic trend lines of the compartmental temperatures to $\mathrm{T}_{\text {cr }}$ (Fig. 6) referred to as the characteristic gain of each compartment and segment, 
Table 3. The sum of squares of variance expressed as percentage of total variance (SS\%) due to environmental warmth and work severity effects

\begin{tabular}{|c|c|c|c|c|c|c|}
\hline & \multicolumn{2}{|c|}{$\begin{array}{c}\text { Environmental } \\
\text { warmth (WBGT) }\end{array}$} & \multicolumn{2}{|c|}{ Work severity } & \multicolumn{2}{|c|}{$\begin{array}{c}\text { Interactions } \\
\text { (WBGT* work } \\
\text { severity) }\end{array}$} \\
\hline & $\mathrm{SS} \%$ & F value & $\mathrm{SS} \%$ & F value & $\mathrm{SS} \%$ & F value \\
\hline $\begin{array}{l}\text { Oxygen demand } \\
(1 / \mathrm{min})\end{array}$ & 0.6 & 2.6 & 84.2 & $241.1 * *$ & 0.9 & $3.4^{*}$ \\
\hline $\begin{array}{l}\text { Heart rate } \\
\text { (beats/min) }\end{array}$ & 4.6 & 2.7 & 63.4 & $203.4 * *$ & 1.3 & $3.7^{*}$ \\
\hline $\mathrm{T}_{\mathrm{cr}}\left({ }^{\circ} \mathrm{C}\right)$ & 1.4 & 1.0 & 6.3 & $3.1^{*}$ & 0.8 & 0.6 \\
\hline Sweat loss & & & & & & \\
\hline $\begin{array}{l}(\mathrm{gm} / \mathrm{min}) \\
\mathrm{T}_{\mathrm{sk}} \text { head }\left({ }^{\circ} \mathrm{C}\right)\end{array}$ & $\begin{array}{l}76.3 \\
19.9\end{array}$ & $\begin{array}{r}253.8^{* *} \\
25.5^{* *}\end{array}$ & $\begin{array}{r}0.5 \\
19.0\end{array}$ & $\begin{array}{c}1.1 \\
16.2 * *\end{array}$ & $\begin{array}{l}0.6 \\
1.4\end{array}$ & $\begin{array}{l}2.1 \\
1.8\end{array}$ \\
\hline $\mathrm{T}_{\mathrm{sk}}$ trunk $\left({ }^{\circ} \mathrm{C}\right)$ & 21.6 & $27.7 * *$ & 18.5 & $15.8 * *$ & 1.4 & 1.8 \\
\hline $\mathrm{T}_{\mathrm{sk}} \operatorname{arm}\left({ }^{\circ} \mathrm{C}\right)$ & 25.6 & $34.3 * *$ & 15.8 & $14.1 * *$ & 1.6 & 2.2 \\
\hline $\mathrm{T}_{\mathrm{sk}}$ hand $\left({ }^{\circ} \mathrm{C}\right)$ & 24.4 & $32.1 * *$ & 16.2 & $14.2 * *$ & 1.8 & 2.4 \\
\hline $\mathrm{T}_{\mathrm{sk}} \operatorname{leg}\left({ }^{\circ} \mathrm{C}\right)$ & 24.8 & $33.0 * *$ & 16.2 & $14.3 * *$ & 1.7 & 2.3 \\
\hline $\mathrm{T}_{\mathrm{sk}}$ feet $\left({ }^{\circ} \mathrm{C}\right)$ & 21.1 & $25.6^{* *}$ & 16.5 & $13.3 * *$ & 2.1 & 2.6 \\
\hline
\end{tabular}

${ }^{*} * p<0.001 ; * p<0.05$.

and a threshold temperature (segmental triggering response) due to the respective behaviour of the compartments. The segmental skin and fat (SHELL) temperatures tended to diverge beyond a certain threshold $\mathrm{T}_{\mathrm{cr}}$, which was termed as the point of divergence. The segmental core and muscle (CORE) temperature tended to converge at a threshold $\mathrm{T}_{\mathrm{cr}}$, which was termed as the point of convergence. The span between the points of divergence and convergence provided a quantitative estimate of the segmental gradient for heat transfer (Table 4). It was noted that head was the segment where the triggering of divergence of skin and fat initiated at the minimum $\mathrm{T}_{\text {cr }}$ and the convergence of core and muscle was also seen at lower $\mathrm{T}_{\mathrm{cr}}$, compared to other segments. In other words, the CORE-SHELL gradient of the head was relatively large, and this might be attributed to greater heat sensitivity of the head region, due to the constituent parts and thermo-receptor innervations.

\section{Tolerance time to work in hot environment}

The generalized body heat balance equation (eqn. 1), the compartment and segmental reference of the temperature gradient, heat conductance of the body compartments, and the heat exchange coefficients yielded the overall rate of change in $\mathrm{T}_{\text {cr }}$, (Fig. 7). The trend in the rate of change in $\mathrm{T}_{\mathrm{cr}}$ showed significant difference $(p<0.01)$ between the moderate and heavy work at environmental warmth beyond $34.9^{\circ} \mathrm{C}$ WBGT. Therefore, taking the initial $\mathrm{T}_{\mathrm{cr}}$ and the limit value, the tolerance time was estimated, as given in Fig. 8.

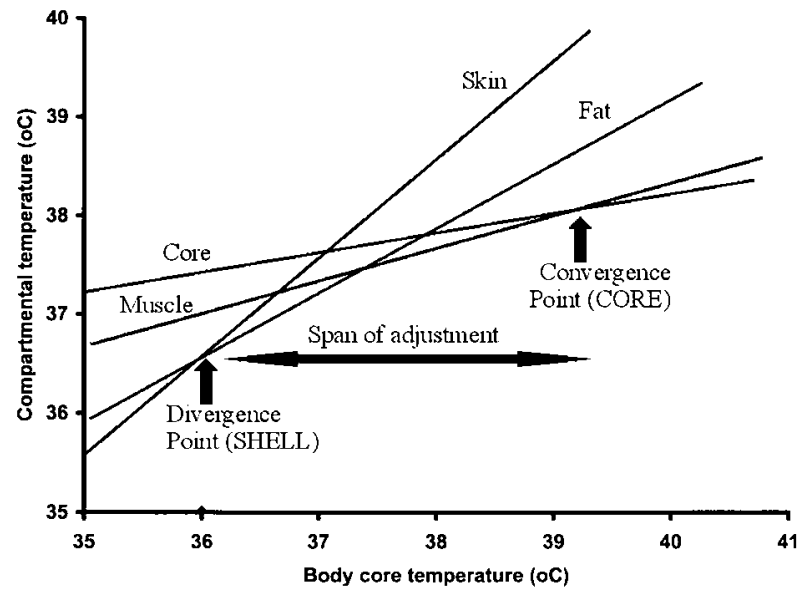

Fig. 6. The schematic trend lines between $T_{\text {cr }}$ and compartmental temperatures, showing the segmental triggering point of divergence and convergence of compartmental temperatures

In the present study, the volunteers exceeded $39^{\circ} \mathrm{C} \mathrm{T}_{\text {cr }}$ in most exposures, and this was referred to as the limit of tolerance of the farmers to work in hot environment. The distribution of duration of the work to the point, at which the exposure was discontinued, had an exponential nature of decay (eqn. 2) with the increase in WBGT.

Tolerance time $(\min )=1841 \mathrm{e}^{-0.103 \text { WBGT }}(\mathrm{r}=0.497$; $p<0.001)$ eqn. (2)

During the moderately heavy work, the tolerance time 
Table 4. Segmental temperature triggering response, referred to as compartmental divergence (SHELL) and convergence points (CORE) in entire range of exposure

\begin{tabular}{lcccc}
\hline Segments & \multicolumn{2}{c}{$\begin{array}{c}\text { Skin-fat divergence } \\
\left(\text { SHELL) }\left({ }^{\circ} \mathrm{C}\right)\right.\end{array}$} & $\begin{array}{c}\text { Core-muscle convergence } \\
\left(\text { CORE) }\left({ }^{\circ} \mathrm{C}\right)\right.\end{array}$ \\
\cline { 2 - 5 } & $\begin{array}{c}\text { Divergence } \\
\text { point }\end{array}$ & $\begin{array}{c}\mathrm{T}_{\text {cr }} \text { at } \\
\text { divergence }\end{array}$ & $\begin{array}{c}\text { Convergence } \\
\text { point }\end{array}$ & $\begin{array}{c}\mathrm{T}_{\text {cr }} \text { at } \\
\text { convergence }\end{array}$ \\
\hline Head & 35.9 & 35.7 & 39.0 & 39.5 \\
Trunk & 36.0 & 35.9 & 37.1 & 40.5 \\
Arm & 35.7 & 35.9 & 37.1 & 40.1 \\
Hand & 36.0 & 36.0 & 37.0 & 40.1 \\
Leg & 35.9 & 35.9 & 37.0 & 40.1 \\
Feet & 36.0 & 36.2 & 37.0 & 40.2 \\
\hline
\end{tabular}

was observed highest as $81 \pm 19 \mathrm{~min}$ at $34.4^{\circ} \mathrm{C}$ WBGT (Fig. 8 ), but in heavy work, at $34.9^{\circ} \mathrm{C}$ WBGT, the tolerance time was less than an hour $(49 \pm 23 \mathrm{~min})$. At highest levels of environmental warmth (e.g., 41.4 and $42.2^{\circ} \mathrm{C}$ WBGT), the tolerance time dramatically dropped to less than $30 \mathrm{~min}$ in moderate and heavy work. The data indicated that the engagement of the farmers to work at the equivalent metabolic levels cannot be pursued continuously even at the lowest level of the experimental condition $\left(34.4^{\circ} \mathrm{C}\right.$ WBGT).

\section{Discussion}

A vast population in the tropical farming is habitually exposed to extremely hot environment as well as to high severity of work, and at a risk of heat casualty and other health hazards ${ }^{10,30}$. Evidences of large-scale casualty from different regions have often been reported in the national dailies $^{31}$. The compiled report of six newspapers of Orissa (Eastern India) noted 1,470 deaths and 1,662 injuries in the year 1998-99 due to severe heat wave. Fatality due to heat stroke among the farmers was over $11 \%$ of the total number of farm accidents. The present environmental chamber study included farmers who underwent climatic exposures (WBGT (inside) ranged from $34.4 \pm 1.5^{\circ} \mathrm{C}$ to $42.2 \pm 1.5^{\circ} \mathrm{C}$ ), against which the heat exchange characteristics and the physiological functions were evaluated. This longitudinal investigation is perhaps the first of its kind to examine the magnitude of physiological strains to extremely high environmental warmth that prevails in tropical outdoor farming.

The study showed the characteristic trends in the cardiovascular and thermoregulatory parameters, substantiating that the dominant effects of work and heat stress are reflected in the responses. Two-way ANOVA indicated that the oxygen demand, heart rates and $\mathrm{T}_{\mathrm{cr}}$ were significantly influenced by the work severity, and the relative effects of work severity were much greater than would be expected by chance after allowing for the effects of environmental warmth. The sweating response became particularly noticeable at higher levels of environmental warmth (e.g., 41.4 and $42.2^{\circ} \mathrm{C}$ WBGT), when the sweating was significantly more in heavy work compared to the moderate severity. In the present context, it was noted that the revised ISO 7933 standard $^{4)}$ describes a prediction model (PHS index $)^{32)}$ of heat balance of the human body and to estimate maximum allowable exposure times in response to the working conditions. The detailed analysis of the PHS index was beyond the scope of the study, however, with the present data of the farmers for the thermal exposures ranging from 34.4 to $42.2^{\circ} \mathrm{C}$ WBGT (inside), there was a general agreement in the prediction of sweat rate $(\sim 5 \%$ overestimation) and the internal core temperature $(\sim 3 \%$ underestimation $)^{32}$. The international standard addressed the exponential averaging of the skin temperature. The present study strongly reiterated that both the environmental warmth and work severity had independent discernable effects on the dynamic equilibrium of the central and peripheral mechanism to regulate the body temperature ${ }^{33)}$. The response behaviour of the segmental $\mathrm{T}_{\mathrm{sk}}$ suggested its role as the first rank indicator of the bodily heat strain. The regression analysis between the WBGT index and the segmental $\mathrm{T}_{\mathrm{sk}}$ showed larger slopes of the regression lines in moderately heavy work. In spite of a higher level of $\mathrm{T}_{\mathrm{sk}}$ maintained in heavy work, the smaller slopes suggested slow build up in the segmental $\mathrm{T}_{\mathrm{sk}}$ due to less space for body adjustment against the critically high levels of $\mathrm{T}_{\mathrm{cr}}$.

The nature of the peripheral response was further substantiated in the heat balance analysis of the compartments (core, muscle, fat and skin) of different segments. The span of convergence of the segmental core and muscle temperatures to the divergence of segmental skin and fat temperatures, CORE-SHELL reflected as a quantitative estimate of the segmental gradient for heat transfer (Table 4). Accordingly, the summation of the compartmental and segmental heat exchange (see eqn. 1 ) yielded the overall rate of change in $\mathrm{T}_{\text {cr }}\left(0.06\right.$ to $\left.0.12^{\circ} \mathrm{C} / \mathrm{min}\right)$, which showed significant difference between the moderate and heavy work (Fig. 7).

Pandolf and Goldman ${ }^{34)}$ and Mairiaux and Malchaire ${ }^{35)}$ suggested that the $\mathrm{T}_{\text {cr }}$ of 39 to $40^{\circ} \mathrm{C}$ might be taken as the tolerance limits for men at work in hot environment, in view of the critical thermal maximum (i.e., the least high $\mathrm{T}_{\text {cr }}$ that is lethal to a human being $)^{36}$. The present volunteers surpassed $39^{\circ} \mathrm{CT}_{\text {cr }}$ in most exposures beyond $34.4^{\circ} \mathrm{C}$ WBGT (Fig. 8), suggesting that the farmers supposedly reached to 


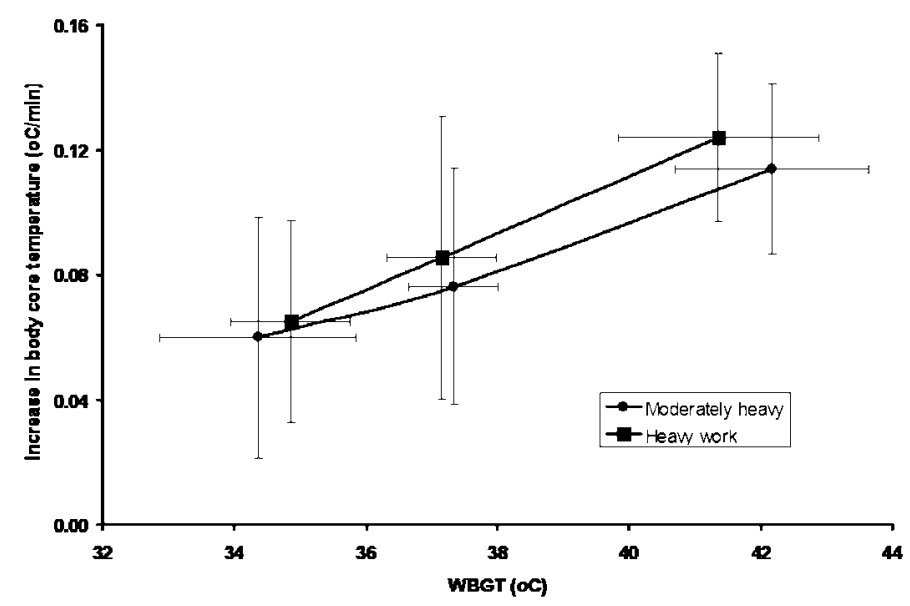

Fig. 7. The rate of change in $T_{c r}$ in moderate heavy and heavy work at different environmental warmth.

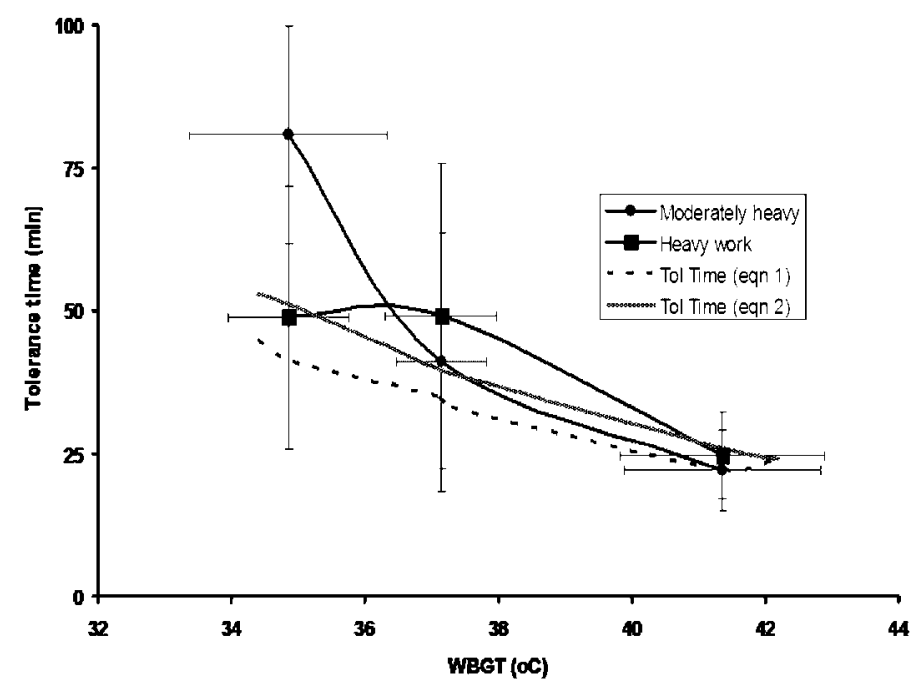

Fig. 8. Heat tolerance time of the farmers at different environmental warmth. Estimated tolerance times (eqn. 1 and 2) are illustrated.

their limit of tolerance. The basic reason to predict the limit of tolerance is that at extremely hot environment, the physiological and other sensory responses might be elevated to an extent that the humans are unable to maintain $\mathrm{T}_{\text {cr }}$ within a reasonable range. The cellular structures, enzyme systems, and other chemical and physical processes might be affected, culminating to hyperthermic illnesses or disorders ${ }^{37)}$. The farming activities categorized as moderately heavy work cover nearly two-thirds of total man-hours, and the heavy work takes about $12 \%$ of the total man hours involved in farming $^{388}$. With such a high level of sustained metabolic and environmental load, even the naturally acclimatized tropical farmers might be at risk of decreased ability to recruit motor units and work motivation.

Therefore, by defining the criteria limit of $\mathrm{T}_{\text {cr }}$ of $\sim 2.5^{\circ} \mathrm{C}$ gradient from the basal $\mathrm{T}_{\text {cr }}$ and the rate of change in $\mathrm{T}_{\mathrm{cr}}$ at a given condition, the tolerance times were arrived at (Fig. 8). Also, the tolerance time of the farmers was observed as the duration of the work to the point at which the exposure was discontinued and predicted with reference to WBGT values (eqn. 2). Each method of estimation of the tolerance time, either from the model application in the rate of change in $\mathrm{T}_{\text {cr }}$ (eqn. 1) or directly from the WBGT values (eqn. 2) had certain margins of error. The eqn. 1 underestimated tolerance times by about $12 \%$; whereas the prediction based on eqn. 2 corresponded closely to the observed tolerance 
times. Apart from the complexity in the heat balance analysis and margins of errors in prediction schemes ${ }^{32}$, the approach of estimating tolerance time from eqn. 1 might serve as a good protective limit for combined exposure to work and heat. The simplicity of prediction lies with the eqn. 2 in using WBGT as a criterion. The exponential equation estimated the tolerance time of $55 \mathrm{~min}$ at $34^{\circ} \mathrm{C}$ WBGT, and up to $38^{\circ} \mathrm{C}$ WBGT, the decrease in tolerance time was 4 to 5 min for every degree increase in environmental warmth. Beyond $38^{\circ} \mathrm{C}$ WBGT, the estimated tolerance time decreased by 2 to $3 \mathrm{~min}$ for every degree increase in WBGT. This optimization for men and women farmers at different age groups will have wider application in avoiding heat illnesses and disorders in tropical farming.

\section{Conclusion}

Tropical heat is a potentially harmful physical agent. The teeming millions of farming population are at risk of heat casualty due to the combined stress of high heat and physical activity performed. The first of its kind environmental chamber experimentation generated data on the magnitude of physiological strains and the limits of tolerance to the climatic conditions that prevail in tropical outdoor farming. Both the environmental warmth and work severity had independent discernable effects on the central and peripheral mechanism of thermoregulation; however, the dominant effects of the two were reflected in the responses. The importance was placed on the segmental and compartmental analysis to estimate the CORE-SHELL gradient for heat transfer and the build up in $\mathrm{T}_{\mathrm{cr}}$. Corollary to the development of ISO 7933 standard, the prediction of tolerance times from the transient change in $\mathrm{T}_{\text {cr }}$ or the exponential relationship with the WBGT were useful to suggest the protective limit for men at work in extremely hot environment. The experimental validation of the knowledge for men and women farmers in different age groups will have application in managing heat illnesses and disorders in tropical farming.

\section{References}

1) WHO (1969) Health factors involved in working under conditions of heat stress, Technical Report Series No. 412, WHO, Geneva.

2) ISO 7243 (1989a) Hot environments—estimation of heat stress on working man, based on the WBGT index (wet bulb globe temperature), ISO, Geneva.

3) ISO 7933 (1989b) Hot environments-analytical determination and interpretation of thermal stress using calculation of required sweat rate, ISO, Geneva.
4) ISO 7933 (2004) Ergonomics of the thermal environmentanalytical determination and interpretation of heat stress using calculation of the predicted heat strain, ISO, Geneva.

5) National Institute of Occupational Health and Safety (NIOSH) (1986) Occupational exposure to hot environments. Revised criteria, U.S. Department of Health, Education and Welfare, Washington D.C.

6) Malchaire J (1990) State of the art in heat stress evaluation and its future in the context of the European directives. Annals Occup Hyg 24, 125-36.

7) McNeill MB, Parsons KC (1999) Appropriateness of international heat stress standards for use in tropical agricultural environments. Ergonomics 42, 779-97.

8) Kampmann B, Piekarski C (2000) The evaluation of workplaces subject to heat stress: can ISO 7933 (1989) adequately describe heat strain in industrial workplaces? Appl Ergon 31, 59-72.

9) Nag PK (1996) Criteria for recommended standards for human exposure to environmental heat. A report: ministry of environment and forests, Government of India (No. 19/45/ 91- RE), National Institute of Occupational Health, (ICMR), Ahmedabad, India.

10) Nag PK, Sebastian NC, Malvankar MG (1980) Effective heatload on agricultural workers during summer season. Indian J Med Res 72, 408-15.

11) National Institute of Occupational Health (NIOH) (1978) Occupational health problems among workers handling virginia tobacco, Ann Report, 30-40, NIOH, Ahmedabad, India.

12) National Institute of Occupational Health (NIOH) (1979) Health status of tea plantation workers with special reference to their occupation, Ann Report, 153-75, Ahmedabad, India.

13) Kenney WL, Havenith G (1993) Heat stress and age: skin blood flow and body temperature. J Ther Biol 18, 341-4.

14) Olesen $B W$ (1995) International standards and the ergonomics of the thermal environment. Appl Ergon 26, 293-302.

15) Montain SJ, Sawka MN, Cadarette BS, Quigley MD, McKay JM (1994) Physiological tolerance to uncompensable heat stress: Effects of exercise intensity, protective clothing and climate. J Appl Physiol 77, 216-9.

16) Nag PK, Bandopadhaya P, Ashtekar SP, Kothari D, Desai H, A Nag (1996) Human work capacity in combined stress of work and heat. J Hum Ergol 25, 105-14.

17) Nag PK, Ashtekar SP, Nag A, Kothari D, Bandyopadhyay P, Desai H (1997) Human heat tolerance in simulated environment. Indian J Med Res 105, 226-34.

18) Indian Council of Medical Research (ICMR) (2000) Ethical guidelines for biomedical research on human subjects, 177, ICMR, New Delhi.

19) Fox RH, Solman AJ, Issacs R, Fry AJ, MacDonald IC (1973) A new method for monitoring deep body temperature from the skin surface. Clin Sci 44, 81-6.

20) Nag PK, Goswami A, Pradhan CK, Ashtekar SP (1986) Convergence of surface and deep body temperature in combined stress of metabolic and environmental warmth. Indian J Med Res 84, 418-23. 
21) Beshir MY, Ramsey JD (1988) Heat stress indices: a review paper. Int J Ind Ergon 3, 89-102.

22) Malchaire J, Mariaux PH (1991) Strategy of analysis and interpretation of thermal working conditions. Annal Occup Hyg 35, 261-72.

23) Parsons KC (1995) International heat stress standards: a review. Ergonomics 38, 6-22.

24) Peters $H$ (1995) Testing climatic indices in the field. Ergonomics 38, 86-100.

25) Werner J, Buse M (1988) Temperature profiles with respect to inhomogeneity and geometry of the human body. J Appl Physiol 65, 1110-8.

26) Nag PK, Bandyopadhyay P (2003) Biophysical modeling of human heat exchange phenomena. In: Humanizing work and work environment, Ray GG, Nag PK and Ganguli A (Eds.), Quest Publications, Mumbai.

27) Nag PK (1984) Convective and evaporative heat transfer coefficients of the persons in different activities. J Hum Ergol 13, 43-8.

28) Gagge AP, Fobelets AP, Berglund LG (1986) A standard predictive index of human response to the thermal environment. ASHRAE Transactions 92, 709-31.

29) Nag PK, Nag A (2004) Drudgery, accidents and injuries in Indian agriculture. Ind Health 42, 149-62.

30) Kahakonen E, Swai D, Dyauli E, Monyo R (1992) Estimation of heat stress in Tanzania by using ISO heat stress indices.
Appl Ergon 23, 95-100.

31) Orissa University of Agricultural Engineering and Technology (OUAT), Department of Farm Machinery and Power, All India Coordinated Research Project on Human Engineering and Safety in Agriculture (2002) Annual report, Bhubaneshwar.

32) Malchaire J, Piette A, Kampmann B, Mehnert P, Gebhard H, Havenith G, Den Hartog E, Holmer I, Parsons K, Alfano G, Griefahn B (2001) Development and validation of the predicted heat strain model. Ann Occup Hyg 45, 123-35.

33) Heising M, Werner J (1985) Differential heating of trunk and other extremities: effects on thermoregulation mechanisms. Eur J Appl Physiol 54, 79-84.

34) Pandolf KB, Goldman RF (1978) Convergence of skin and rectal temperatures as a criterion for heat tolerance. Aviat Space Environ Med 49, 1095-101.

35) Mairiaux PH, Malchaire J (1985) Workers self-pacing in hot conditions: a case study. Appl Ergon 16, 85-90.

36) Bynum GD, Pandolf KB, Schuette WH, Goldman RF, Lees DE Whang-Peng J, Atkinson ER, Bull JM (1978) Induced hyperthermia in sedated humans and the concept of critical thermal maximum. Am J Physiol 235, R228-36.

37) Wildeboor J, Camp J (1993) Heat stress, its effects and control. AAOHN J 41, 268-74.

38) Nag PK, Sebastian NC, Malvankar MG (1980) Occupational workload in Indian agricultural workers. Ergonomics 23, 91-102. 